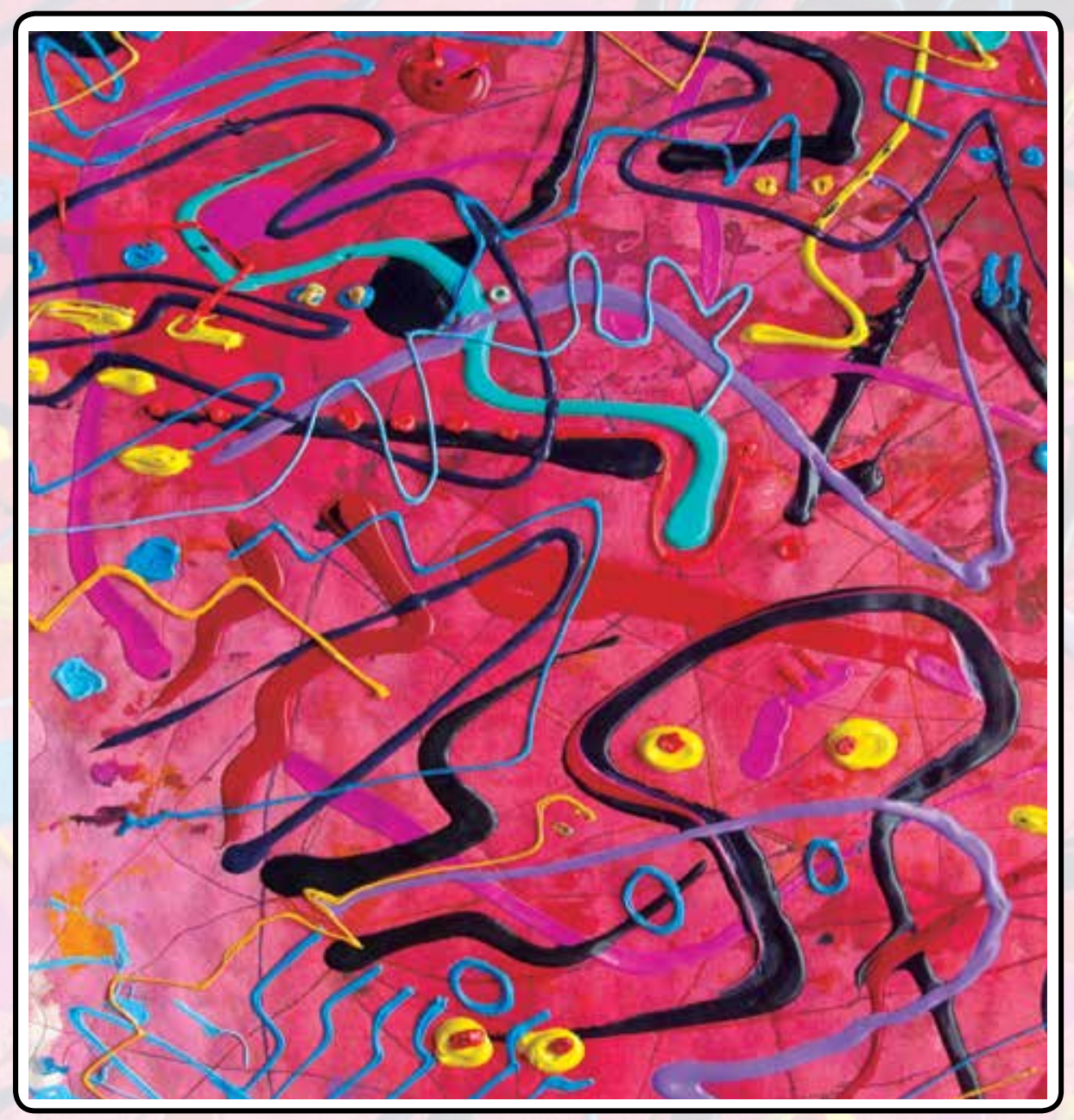

Camilo Umaña V. Sin título Acrílico sobre Lienzo 70 x 40 



\title{
DEMOCRACIA Y DESARROLLO ECONÓMICO EN AMÉRICA LATINA ${ }^{1}$
}

DEMOCRACY AND ECONOMIC DEVELOPMENT IN LATIN AMERICA

María Eugenia Bonilla Ovallos ${ }^{2}$

\begin{abstract}
Resumen
Los conceptos de democracia y desarrollo económico han presentado a lo largo del tiempo grandes modificaciones que han complejizado su estudio y su medición. Pese a ello, varias investigaciones han establecido la existencia de relaciones causales entre democracia y desarrollo económico. Este trabajo realiza un análisis comparativo entre la evolución de estas dos variables en algunos países de América Latina, a partir de la idea de que mejores índices de democracia son el resultado del progreso en el nivel de desarrollo de los países, como consecuencia de que las decisiones políticas, sociales y económicas que han sido promovidas, han contribuido a satisfacer las demandas sociales existentes.
\end{abstract}

\section{Palabras clave}

Democracia, Desarrollo Económico, Instituciones, América Latina

\section{Clasificación JEL O1, O43}

\begin{abstract}
The concepts of democracy and economic development have been presented over time major changes that have more complex study and measurement, even so, several studies have shown the existence of casual relationships between democracy and economic development. This paper makes a comparative analysis of the evolution of these variables in Latin America countries based on the idea that democracy best rates are the result of progress in the level of development countries as a result of political decisions, social and economic conditions that have been promoted they have helped to know the demands of the actual society.
\end{abstract}

Keywords

Democracy, Economic Development, Institutions, Latin America

1 Este trabajo se realizó con el apoyo del Instituto de Estudios Políticos IEP de la Universidad Autónoma de Bucaramanga (Colombia), dentro de la línea de investigación en Políticas Públicas, del Grupo de Investigación de Ciencia Política.

2 Doctoranda en Procesos Políticos Contemporáneos Latinoamericanos de la Universidad de Salamanca (España). Economista y Especialista en Administración de Empresas. Investigadora del Instituto de Estudios Políticos (IEP) de la Universidad Autónoma de Bucaramanga (Colombia). Correo electrónico: mbonilla566@unab.edu.co 


\section{Introducción}

El concepto de democracia ha presentado a lo largo del tiempo grandes modificaciones en cuanto a la definición y la forma en que se aplica, lo cual ha complejizado su estudio y su medición. En las sociedades antiguas solía definirse la democracia como un mal gobierno, Aristóteles y Kant compartían esta postura debido a que existía una idea negativa frente al poder de las mayorías, las cuales no gobernarían en pro del interés común sino a favor de sus intereses particulares. En la actualidad, la democracia es un sistema político basado en un principio de legitimidad, llamado a resolver los problemas de bienestar y es percibida como un ideal, además de ello el concepto ha trascendido el ámbito exclusivamente político y es también asociado con aspectos sociales y económicos, lo que contribuye a que actualmente la democracia sea percibida como una utopía.

Por su parte, lo que entendemos por desarrollo económico también se ha transformado en el tiempo. La perspectiva clásica solía asociarlo con aspectos ligados al crecimiento económico, al presentar una definición bastante minimalista y restringida del desarrollo. No obstante, la imposibilidad que tuvo el crecimiento para traducirse en mejores condiciones de vida para la población, generó la necesidad de complementar el concepto y hacer énfasis en que hablar de desarrollo económico trasciende al aumento porcentual de los bienes y servicios finales que se producen dentro de las fronteras de un país durante un período de tiempo específico, e implica en las posturas más modernas asociarlo con el bienestar social y con el desarrollo de las capacidades, las potencialidades y las libertades que aumentan las posibilidades que tiene el ser humano para ser feliz.

Por tanto, la complejidad de los conceptos hace que medir la democracia y el desarrollo resulte un gran reto. Establecer las relaciones causales existentes entre las dos variables mencionadas, lo es aún más. Sin embargo, varios investigadores se han enfrentado a él y han señalado que unas buenas condiciones socioeconómicas favorecen el establecimiento de la democracia y el mantenimiento del régimen. Para Dahl la poliarquía ${ }^{3}$ está significativamente asociada con altos niveles de desarrollo socioeconómico (1971, p. 69) y comparte la tesis de Russett cuando éste sostiene que los países que tienen niveles altos de desarrollo socioeconómico presentan mayores probabilidades de tener un régimen político democrático, y al mismo tiempo señala que los países que cuentan con este tipo de régimen suelen también presentar mejores condiciones socioeconómicas. No obstante, es importante hacer claridad que cuando se estudia dicha causalidad también se presentan casos divergentes, ya que no es cierto que la poliarquía esté presente en todos los países con altos niveles de bienestar socioeconómico.

3 Entendida esta como sinónimo de democracia, dada la diferencia entre la realidad del régimen y su definición idealista. 
El objetivo de este trabajo es realizar un análisis comparativo entre la evolución de la democracia y el desarrollo económico en algunos países de América Latina. La selección de los casos se realiza según la base de datos establecida por los índices de democracia y es comparada con la evolución de la renta per cápita de cada país, debido a que la teoría existente sobre la relación causal entre estas variables, ha utilizado este indicador como medida de desarrollo. Se espera respaldar la hipótesis que mejores índices de democracia son el resultado del progreso en el nivel de desarrollo de los países, como consecuencia de que las decisiones políticas, sociales y económicas que han sido promovidas, han contribuido a satisfacer las demandas sociales existentes.

La presente investigación está estructurada en cuatro partes. En la primera de ellas se hace una revisión teórica de los conceptos de democracia y desarrollo económico, con alusión a la forma en que éstos se han transformado desde la antigüedad hasta nuestros tiempos. En segundo lugar, se establecen las relaciones causales entre democracia y desarrollo económico basándose en las observaciones realizadas por diversos investigadores y que representan el soporte teórico para esta área de estudio. En la tercera parte se explican los aspectos metodológicos que sustentan la observación de la relación causal entre estos dos conceptos en América Latina, y se justifica la selección de los casos observados. En la cuarta parte se realiza comparación de la evolución de la democracia y el desarrollo económico en algunos países latinoamericanos y finalmente se presentan las conclusiones con base en los resultados obtenidos.

\section{Dos conceptos clave: democracia y desarrollo}

Las conceptualizaciones que se han desarrollado sobre la democracia a través del tiempo son diversas, sus componentes o atributos difieren con regularidad entre los autores lo que dificulta su comprensión y medición. Giovanni Sartori establece que la transición entre el concepto antiguo y moderno de la democracia, a través de la ampliación de su ámbito de acción, hace que el estudio de ésta sea cada vez más complejo.

En su artículo sobre la democracia, Sartori establece las diferencias que han surgido a través del tiempo en cuanto a la percepción del concepto. En las sociedades antiguas solía definirse la democracia como un mal gobierno, en la actualidad la democracia es un sistema político basado en un principio de legitimidad, llamado a resolver los problemas de bienestar y es percibida como un ideal. En ningún caso, la democracia tal y como es coincide, ni coincidirá jamás con la democracia tal y como quisiéramos que fuera (Satori, 1992, p. 31). Y se convierte en ideal en la medida en que deja de ser entendida como un concepto netamente político y comienza a relacionarse con un concepto social y, por lo tanto, económico. 
Otra diferencia que establece el autor entre los antiguos y los modernos es el concepto de mayoría que pasa de ejercer un poder directo (democracia directa) a un poder controlado y limitado (democracia representativa) ${ }^{4}$, como consecuencia del crecimiento demográfico de los pueblos y la universalización del derecho al voto. De igual forma cambia la relación de servicio entre los ciudadanos y el Estado, al reconocer el valor de la persona de forma intrínseca, bajo esquemas de libertad y dignidad. Y, finalmente, la transición se da entre democracia pura, liberalismo, y democracia moderna (democracia liberal y generalmente representativa). La idea del autor es que fuera del Estado democrático-liberal no existe ni libertad, ni democracia.

La democracia moderna para Sartori se basa en los principios de libertad política ${ }^{5}$, igualdad jurídico-política ${ }^{6}$, legitimidad y bienestar. Es un sistema pluripartidista en donde las mayorías a través de sus representantes, gobiernan respetando los derechos de las minorías, supliendo las demandas de la sociedad en un esquema de competencia abierta y periódica dentro del mercado electoral.

Los griegos, quienes contemplaban el desarrollo de la democracia dentro de las fronteras de la ciudad-nación, fueron testigos de la primera transformación que sufrió el concepto, debido al desarrollo del moderno Estado-Nación que obligó al surgimiento de un conjunto de instituciones nuevas, lo que afectó de forma significativa las prácticas democráticas que hasta entonces habían imperado. Así, durante varios milenios distintas fuentes de pensamiento (griegas, romanas, medievales, renacentistas y modernas) han alimentado el concepto y generado metamorfosis en él.

Varias son las posiciones que se presentan en torno al concepto de democracia. En primer lugar, se encuentran los críticos que se oponen a ella, como Platón y Aristóteles, quienes consideran que es contraproducente e inconveniente aplicarla. Otros, como Robert Michels, consideran que es conveniente desarrollarla pero intrínsecamente imposible hacerlo. Y finalmente, aquellos críticos benevolentes que simpatizan con ella y quisieran preservarla, pero que necesariamente critican algunos de sus aspectos. Esas tres posiciones nos llevan a pensar que la teoría de la democracia es bastante compleja y, por tanto, se hace necesario alejarla del concepto utópico y estudiarla pensando siempre en sus límites y en sus posibilidades.

Según el PNUD la democracia excede un método para elegir a quienes gobiernan, es también una manera de construir, garantizar y expandir la libertad, la justicia y el progreso material y espiritual. Es, a la vez, un fin y un instrumento, dado que contiene procedimientos para el acceso y el ejercicio del poder, pero también es el resultado de esos procedimientos.

4 Sartori respalda esta apreciación diciendo que la democracia indirecta, no es únicamente la atenuación de la democracia directa, sino también un correctivo que permite escapar de las radicalizaciones de los procesos directos (1992, p. 36)

5 Entendida como la posibilidad que tiene los ciudadanos a no estar expuestos a la voluntad de los poderosos.

6 Iguales leyes, iguales derechos, iguales libertades. 
Cuando tiende a identificarse la democracia con un simple régimen político se priva a los individuos de la capacidad que tienen, como actores políticos reconocidos de gestionar e impulsar cambios o reestructuraciones en pos del mejoramiento tanto individual como colectivo. Más que el reconocimiento de la igualdad del ciudadano establecida por la democracia social de la que habla Sartori, esta expansión de la democracia al ámbito social implica la necesidad de que el ciudadano descubra la posibilidad que tiene de influir a través de la política en las condiciones sociales de su entorno. Eso deja claro que no basta con ser reconocido como ciudadano, sino que es fundamental ejercer la ciudadanía en un Estado que garantice el acceso a la participación y se legitime mediante un ejercicio representativo eficiente. Según el PNUD Restringir la democracia al régimen político la expropia de cualquier relación activa frente a la injusticia social que resulta de un Estado ineficaz (PNUD 2004, p. 54).

Para Dahl la democracia también es un ideal, hipotéticamente es posible concebirla (...) sólo puede servir a modo fiel de contraste para valorar el grado de aproximación de los distintos sistemas al ideal teórico (Dahl, 2002, p.7128) . Este autor plantea que para el establecimiento de la democracia y, por tanto, para que se garantice la igualdad de oportunidades, es necesario que existan tres condiciones fundamentales (oportunidad de formular preferencias, de manifestar preferencias y recibir igual trato por parte del gobierno en la ponderación de las preferencias). Desde luego, las tres condiciones fundamentales que señala el autor sólo pueden darse en la medida en que existan garantías institucionales y, él identifica ocho.

Para medir estas ocho garantías en diversos países, Dahl establece dos dimensiones representadas en un eje cartesiano: el debate público y la capacidad de representación. De acuerdo al grado en que se garantice la existencia de estas dos dimensiones se tendría democracia, hegemonía cerrada, hegemonía comprensiva ${ }^{7} \mathrm{u}$ oligarquía competitiva $^{8}$. Finalmente, concluye que la mayoría de los países se encuentran en el centro del cuadrante, por lo que están en un proceso de democratización.

Para Dahl, en la medida en que estas dos dimensiones se garantizan aumenta la probabilidad de que se establezcan poliarquías $^{9}$, y ello implica posibilidades de conflicto para quienes detentan el poder, debido a que establecen mayores oportunidades para que los opositores tengan éxito. Sin embargo, abrirle espacio a la oposición o suprimirla depende del costo de oportunidad de cada una de estas opciones. Por ello la democracia, entendida como el reconocimiento del valor del individuo como agente político y social, necesita liberarse de falencias como la opresión, la desigualdad, la injusticia. Al ser un régimen competitivo lleva inmersa una filosofía pluralista que se desarrolla en torno a un proceso electoral.

Mayor representatividad, menor debate.

Mayor debate público menor representación.

Utiliza este término porque considera que no existe ningún régimen totalmente democratizado. 
La legitimidad del gobierno depende de la capacidad en que éste, en su calidad de representante y a través sus políticas públicas, planteé soluciones de forma eficaz y eficiente a las presiones sociales que se generen.

Los miembros del gobierno son los delegados a quienes el pueblo ha entregado su soberanía mediante elecciones libres de competencia partidista, esperando que dichas autoridades representen los intereses de la ciudadanía. Ellos, a través del poder legislativo, representado en el parlamento, tienen la potestad entre otras cosas, de establecer las reformas económicas, políticas y sociales, así como de aprobar el presupuesto nacional, que influirá de forma significativa en el desarrollo económico de los países. Sin embargo, la democracia representativa ha sido cuestionada debido a fallas que se han presentado dentro del contexto institucional bajo el que se encuentra articulada. El parlamento, órgano que tiene en sus manos las directrices de este tipo de políticas, se ha visto envuelto en situaciones de corrupción engorrosas, que cuestionan su capacidad para operar en función del bienestar general.

Es, precisamente, el desarrollo económico el concepto que engloba los distintos aspectos que conllevan al establecimiento de condiciones de vida digna para la población y que dependen en gran parte de las decisiones que se toman en materia de políticas públicas, por parte de los organismos de poder. Desde luego, cuando surge el concepto de desarrollo económico en el siglo XVIII, los economistas clásicos limitan su definición a la exclusiva asociación de éste con el nivel de crecimiento económico, es decir, con la variación porcentual que experimenta la producción de bienes y servicios corrientes dentro de las fronteras de un país, durante un período determinado de tiempo.

Sin embargo, el dinamismo de la economía mundial al que conllevó la Revolución Industrial, que terminó por afectar los niveles de crecimiento económico en todos los rincones del planeta, permitió evidenciar que no bastaba con garantizar el crecimiento para mejorar las condiciones de vida de la población y que, si bien, éste era necesario para estimular el desarrollo económico, no era suficiente para alcanzarlo. Es así como el concepto de desarrollo económico comenzó a transformarse a lo largo del tiempo, inicialmente diferenciándose del crecimiento económico y relacionándose con una multitud de indicadores asociados a la eliminación de la pobreza, la desnutrición, la mortalidad infantil, el aumento de la esperanza de vida, el acceso a la red de saneamiento, agua potable, salud y educación, entre otros. Es decir, el desarrollo económico está condicionado en su definición por la satisfacción de las necesidades básicas.

La realidad multidimensional que presenta este concepto dificulta los análisis que se desarrollan al respecto, debido a los errores en los que suele incurrirse cuando se pretende reducir una realidad compleja a un dato, expresado a través de un indicador de tipo cuantitativo. No obstante, el indicador que generalmente es asociado con el desarrollo económico es el PIB per cápita, entendido como un indicador que relaciona el crecimiento económico con el crecimiento demográfico, señalando la porción de 
producto que correspondería a cada ciudadano, en caso que éste se distribuyera homogéneamente entre la población. Es importante señalar, que en cuanto al uso del PIB per cápita como medida de desarrollo, existen varias críticas y de hecho en varios casos se recomienda usar indicadores alternativos para su estudio, como es el caso del Índice de Bienestar Económico Sostenible (IBES), Índice de Progreso Real (IPR) o el Índice de Progreso Genuino (IPG).

En la actualidad, el concepto de desarrollo económico, ha adquirido mayor complejidad, en la medida en que se ha vuelto cada vez más ambicioso, dado que se relaciona con la capacidad que tienen los ciudadanos de vivir bajo sus deseos y desarrollar al máximo sus potencialidades y capacidades. Más allá de satisfacer las necesidades básicas y de garantizar el crecimiento económico, las teorías más avanzadas comienzan a relacionarlo con la felicidad que genera el ejercicio de las libertades más elementales del ser humano. Así Pues Amartya Sen señala:

"cuando se analiza la justicia social, existen poderosas razones para juzgar la ventaja individual en función de las capacidades que tiene una persona, es decir, de las libertades fundamentales de las que disfruta para levar el tipo de vida que tiene razones para valorar" (Sen, 2000, P. 67).

Además Sen establece que hablar de desarrollo económico implica hablar de pobreza, pero entendiendo por pobreza, no la escasez de renta que presentan los individuos de una sociedad, sino analizándola desde la perspectiva de las capacidades. Si bien, existe relación entre los niveles de renta y la posibilidad que tienen los miembros de una sociedad para desarrollar sus capacidades, no es correcto afirmar que el simple hecho de tener un nivel de renta alto, implique que las sociedades no sean pobres. El esfuerzo por construir un índice multidimensional que contemple varios indicadores al respecto, no ha dado como resultado el Índice de Desarrollo Humano (IDH).

Es así como los conceptos de democracia y desarrollo económico, han evolucionado en el tiempo, adquiriendo componentes elementales para la garantía del desarrollo continuo de mejores condiciones de vida para la población y convirtiéndose en conceptos tan elaborados para la vida humana, que rayan en la utopía y su constante consolidación termina siendo un objetivo concreto de los gobiernos. Ahora bien, ¿Qué relación existe entre la democracia y el desarrollo? Abordemos a continuación este debate.

\section{Relaciones causales entre Democracia y Desarrollo Económico}

Amplia es la teoría que habla de las relaciones causales entre desarrollo económico y democracia. Algunos autores consideran que unas buenas condiciones socioeconómicas favorecen el establecimiento de la democracia y el mantenimiento del régimen. 
Para Dahl la poliarquía ${ }^{10}$ está significativamente asociada con altos niveles de desarrollo socioeconómico (1971, p. 69). Sin embargo, establece un análisis que parte de diferentes estadios de desarrollo y distintos grados de poliarquía, y establece que en la observación de dichas realidades existen casos divergentes, dado que hay países con niveles bajos de bienestar socioeconómico cuyo régimen político es una poliarquía.

No obstante, esa relación no es la misma en los diversos estadios de desarrollo, por lo que establece que la relación no es lineal, sino curvilínea. Es decir, en el umbral superior e inferior de ingreso per cápita, donde se garantiza o no la existencia de poliarquía, cualquier aumento en la renta per cápita no genera mayor variación en el resultado (Dahl, 1971, p.71).

Por ello, aunque existe una relación causal entre poliarquía y desarrollo socioeconómico ésta no es simple ni va en una sola dirección, por lo que resulta

imposible plantear una teoría que respalde la hipótesis de que para que exista poliarquía es condición necesaria y suficiente un alto grado de desarrollo socioeconómico, ni la hipótesis contraria de que la poliarquía es condición necesaria y suficiente para obtener un alto nivel de desarrollo socioeconómico (Dahl, 1971, p.74).

Para este autor, la probabilidad de que un país desarrolle y conserve una poliarquía, depende de si garantiza o no la disminución de la tasa de analfabetismo, impulsa el desarrollo educativo y comunicativo, establece un orden pluralista y previene las desigualdades extremas entre los estamentos políticos del país.

Una economía evolucionada en términos de desarrollo económico genera un progreso social que impulsa la demanda de participación en un país menos centralizado y genera las condiciones para un orden social más pluralista. Por lo que Dahl establece una relación causal entre economía evolucionada, orden social pluralista y presiones por el sistema político competitivo. Sin embargo, en la perspectiva del autor "mientras el éxito económico amenaza las hegemonías, al demandar liberación política, no representa peligro alguno para las poliarquías que, en cambio, sí tienen que temer al fracaso económico. (Dahl, 1971, p.81).

La realidad hace prever que la cuestión es más compleja aún, debido a que existen sociedades con altos niveles de desigualdad, como es el caso de América Latina ${ }^{11}$, que han logrado mantener la democracia, lo cual no es garantía de que este régimen pueda existir aún bajo dichas condiciones. En parte esto ha sido posible según Dahl por dos razones: la satisfacción de alguna de las demandas reclamadas a través de

10 Entendida esta como sinónimo de democracia, dada la diferencia entre la realidad del régimen y su definición idealista.

11 Esta desigualdad implica no sólo diferencias en términos de riqueza u status, sino también diferencias políticas, debido a que las desigualdades extremas en las fuentes del poder político delimitan las oportunidades de participación. 
las presiones de determinados grupos y la incapacidad de los grupos marginados de ejercer presión. Pero, finalmente, la poliarquía es altamente vulnerable a dichos problemas sociales, dado que la desigualdad no favorece los métodos políticos competitivos.

Por su parte Mainwaring y Pérez (2004) en su estudio sobre la relación causal entre el nivel de desarrollo (grado de modernización) y democracia en América Latina, realizado para el período comprendido entre 1945-1996, en el que analizan datos cuantitativos de 19 países mediante modelos de regresión sofisticados ${ }^{12}$, concluyen que existe una influencia más débil entre el nivel de desarrollo y el surgimiento de regímenes democráticos en esta región, comparado con el que se ha presentado en otras regiones del mundo e incluso con la de los países que se encuentran dentro del mismo rango de renta.

En América Latina, de acuerdo con las observaciones realizadas por los autores, los mayores niveles de crecimiento económico se obtuvieron en regímenes no democráticos. Según sus resultados el crecimiento promedio anual de la renta per cápita en las democracias fue de $1.59 \%$, en las semidemocracias $1.10 \% \mathrm{y}$ en los regímenes autoritarios $1.64 \%$.

El estudio además ratifica la existencia de una relación curvilínea en la que se establecen cuatro fases, es decir, que según los autores precitados la probabilidad de democracia disminuye por encima de un nivel de renta per cápita hasta llegar a un determinado umbral a partir del cual vuelve a aumentar (Mainwaring y Pérez, 2004, p. 2001)

De igual forma Mainwaring y Pérez verifican el argumento que sostienen autores como Lipset (1959) y Diamond (1999) cuando afirman que el trasfondo de esa correlación son los cambios en la estructura de clases que movilizan o garantizan una mayor participación. De hecho, concluyen que en la medida en que el mayor porcentaje de la población trabajadora se dedica a la agricultura más disminuye la probabilidad de la democracia (Mainwaring y Pérez, 2003, p. 206). Sin embargo, consideran que el desarrollo de una clase trabajadora industrial no ha generado un impacto representativo para la democracia. Así mismo, miden la importancia de la educación y encuentran que esta variable no es estadísticamente significativa.

Al observar el comportamiento de la democracia en América Latina identifican tres anomalías: En varios países relativamente prósperos como Argentina. México, Uruguay y Chile se establecieron por un período significativo gobiernos autoritarios. La democracia ha logrado mantenerse por épocas relativamente largas en países pobres como Bolivia, El Salvador, Honduras y Nicaragua. Y finalmente, el desmejoramiento continuo de la calidad de vida de los latinoamericanos desde la

12 Utilizan para sus cálculos cuatro indicadores de democracia: el ACLP, Freedom House, la escala de Polity y la medida tricotómica de Mainwaring. 
década de los 80 no ha generado un retroceso hacia regímenes autoritarios ${ }^{13}$. Por el contrario, estos tuvieron lugar en la década de los 60 y 70, después de que la región experimentara entre 1950 y 1980 niveles de crecimiento promedio anual de la renta per cápita de 116\% (Mainwaring y Pérez, 2003, p. 217).

Ante la preocupación del mantenimiento del régimen debido a que la región posee los niveles más altos de desigualdad en el mundo, Mainwaring y Pérez consideran que el peligro está en la polarización política que puede surgir de las desigualdades y no en las desigualdades per se (Mainwaring y Pérez, 2003, p. 217).

Esta preocupación es compartida por el Programa de Naciones Unidas para el Desarrollo, debido a que a pesar de que en teoría (constitucionalmente) existe el reconocimiento de derechos civiles, sociales y políticos en América Latina, no existen garantías para que éstos sean asegurados. Este organismo plantea que: Dado el alto déficit social, algunos latinoamericanos estarían dispuestos a aceptar un gobierno autoritario si éste resolviera sus situación económica (PNUD 2004, p. 33).

Si bien la universalización del sufragio y la garantía de las elecciones es un componente importante de la democracia, no es suficiente para que ella se complemente: necesita estar acompañada de libertad, justicia y progreso. Para el PNUD la relación causal se desarrolla de la democracia hacia el desarrollo económico una vez se reconozcan los derechos de los ciudadanos. Además incitan a reflexionar sobre el problema de ignorar la viabilidad económica de la democracia. Es decir, al ser éste un régimen sustentado en los principios de libertad y justicia que permite el libre desarrollo de asociaciones que generen demandas organizadas y masivas, puede influir de forma determinante en el mejoramiento de las condiciones económicas de la sociedad, principal fuente de poder. Sin embargo, si esas demandas son ignoradas, se cae en el error de desconocer la viabilidad política de los programas económicos.

Por ello, el Programa de Naciones Unidas para el Desarrollo considera que si esta relación causal entre democracia y desarrollo presenta sus falencias en esta región del mundo, es debido a que se ha pensado a la democracia y a la economía como cuestiones independientes. De aquí el desafío de resolver las tensiones entre estas dos variables. Es necesario no pensar la economía como si no hubiera democracias pobres ni atacar los problemas de la estabilidad democrática independiente de las necesidades de resolver las cuestiones de crecimiento (PNUD, 2004, p. 40). El informe presentado en el 2004 sostiene que el desarrollo económico de los países de América Latina sólo puede alcanzarse a través de la democracia. La razón es que sólo en democracia, quienes son víctimas de la desigualdad y la pobreza, pueden reclamar, movilizarse y generar presión para hacer reales sus derechos.

13 Según la teoría, niveles altos de desarrollo llevarían al establecimiento de regímenes democráticos, en el caso contrario llevarían al establecimiento de gobiernos autoritarios. 
Con respecto a dicha relación causal entre democracia y desarrollo económico, Dahl sostiene que un país con una sociedad democrática avanzada debe garantizar tres aspectos fundamentales: la presencia de gobiernos a gran escala, la posibilidad de que los ciudadanos participen en la vida política con aproximada igualdad y la regulación de las estructuras sociales, económicas y políticas de modo que garanticen la igualdad política y relaciona éstas últimas con la efectividad de las políticas públicas.

De manera que queda claro que la teoría establece una relación causal entre desarrollo económico y democracia, que en algunos casos la dirección de la relación varía y que en otros la relación es sistémica, es decir en ambas direcciones. Sin embargo, ninguna de estas variables es garantía única de la existencia de la otra como lo sostiene la teoría, dado que puede existir, y de hecho existe, democracia sin desarrollo, como también puede existir, y de hecho existe, desarrollo económico sin democracia.

Cuestionar la democracia implica establecer la influencia que ejercen las reglas del juego que determina su desarrollo. Para Diamond (1999), quien la define como la mejor forma de gobierno y ha estudiado las condiciones que favorecen el surgimiento, el mantenimiento y la consolidación de la democracia liberal, en América Latina debido a cuestiones como la pobreza institucional, la ausencia de controles a las instituciones, el carácter disfuncional de su sistema judicial y la violación de los derechos humanos, existe una democracia no liberal. Superar estas falencias implica hacer las estructuras democráticas más liberales, más representativas, accesibles a la rendición de cuentas.

Los regímenes democráticos deben producir buenos resultados políticos, económicos y sociales para legitimarse. La eficacia del sistema político está directamente relacionada con la calidad de la representación. En la medida en que las condiciones y las expectativas de la sociedad mejoran como consecuencia de una reducción del déficit socio-económico, la democracia representativa es funcional dentro del sistema.

\section{Cuestiones metodológicas}

De acuerdo a lo que se ha planteado hasta el momento, el objetivo de este trabajo es realizar un análisis comparativo entre la evolución de la democracia representativa y el desarrollo económico en algunos países de América Latina. Los casos para analizar serán seleccionados con base a la observación comparativa de la evolución de los índices de democracia y de la renta per cápita de cada país. Sin embargo, es necesario hacer énfasis en los errores que pueden surgir de utilizar como indicador de desarrollo el PIB per cápita, cuando el objetivo es analizar las relaciones causales de éste con la democracia y, más aún, con la democracia representativa, debido a que este indicador, por basarse en supuestos de uniformidad, no permite observar 
las disparidades en la distribución del ingreso, cuyos resultados sí están altamente determinados por las decisiones políticas que toma el legislativo en materia económica y social.

Indicadores de desarrollo como el índice de calidad de vida (ICV) o el índice de desarrollo humano (IDH) serían más acertados si lo que pretendemos estudiar es la relación causal entre democracia representativa y desarrollo económico, debido a que se podría determinar si los avances del índice de democracia están relacionados con la satisfacción de demandas sociales, como consecuencia de la intervención eficiente de la representación. Por el contrario, utilizar índices como el PIB per cápita o el índice de libertad económica (ILE) sería más adecuado para observar la forma en que la democracia como régimen político influye en el crecimiento económico y no en el desarrollo, porque éste si bien necesita el crecimiento para mejorar no es garantía del mismo.

Se espera respaldar la hipótesis que mejores índices de democracia son el resultado del progreso en el nivel de desarrollo de los países, como consecuencia de las decisiones políticas, sociales y económicas que han sido promovidas en el parlamento, han contribuido a satisfacer las demandas sociales existentes.

El nivel de pobreza de los países será un indicador utilizado en el análisis debido a que ésta se encuentra relacionada con las decisiones de inversión social implementadas por los representantes políticos, así como las reformas fiscales contribuyen a determinar los niveles de desigualdad en la distribución del ingreso. Cualquier avance en estos indicadores implica que la democracia representativa es efectiva ante las demandas de la sociedad y se espera influya positivamente en la percepción que se tiene del régimen. Entrar a profundizar sobre el impacto de cada una de las reformas económicas, políticas y sociales que se han adelantado en los países es una tarea compleja que no será tratada en ésta primera parte de la investigación.

\subsection{Midiendo la democracia}

Estudiar la democracia implica grades desafíos, uno de los más destacados es establecer índices adecuados para medirla. Pese a que se han utilizado desde mediados del siglo XX algunos métodos estadísticos de inferencia causal y que los esfuerzos por incluir técnicas cuantitativas en el estudio de fenómenos políticos son positivos, aún queda mucho por replantear y mejorar.

Poder analizar un fenómeno tan complejo como la democracia a través de un indicador permite hacer análisis verticales y horizontales, estudios comparados, hallar nuevos indicadores de variabilidad, de cointegración y establecer coeficientes de regresión, en fin, contar con una base de datos permite enriquecer el análisis. Sin embargo, al igual que le sucede a otras ciencias que buscan reflejar una realidad social, que tiene mucho de subjetiva, mediante estudios cuantitativos, se corre el 
riesgo de que al sintetizar diversos atributos del concepto, se pierda información relevante en cada uno de los casos, se presente manipulación de los resultados derivado de sesgos de interés y se reduzca una realidad compleja a un dato, que en algunos casos refleja una realidad multidimensional.

Según un estudio sobre los índices de democracia ${ }^{14}$ realizado por Munck y Verkuilen, los investigadores cuantitativos han prestado poca atención a la calidad del los datos sobre la democracia. Para estos autores los retos de la calidad giran en torno a tres dimensiones: la conceptualización, la medición y la agregación.

A su vez, cada dimensión tiene sus propios desafíos. En cuanto a la conceptualización, el mayor de ellos es la identificación de los atributos que son constitutivos del concepto, (Munck y Verkuilen, 2002, p. 407) dado que éstos deben estar vinculados a la teoría, pero suelen cometerse errores de polarización de los atributos, de manera que se plantean conceptos maximalistas ${ }^{15} \mathrm{o}$ minimalistas ${ }^{16}$.

Una vez establecidos los atributos, el reto consiste en desagregarlos para establecer los componentes de cada uno de ellos. Es fundamental observar la forma en que se relacionan entre sí para evitar problemas de sobreposición ${ }^{17}$, con el objetivo de no cometer errores de redundancia. Inicialmente el enfoque teórico de los índices se basaba en los dos atributos, competencia y participación, establecidos por Dahl (1971, pp. 4-6) pero a través del tiempo se han insertado múltiples atributos ${ }^{18}$.

En cuanto a la medición el reto gira en torno a establecer los indicadores que operacionalicen los componentes desagregados de los atributos. Puede cometerse el error de no reconocer las múltiples manifestaciones empíricas de un atributo conceptual. Otro problema es no reconocer lo inevitable del error de medición, es decir, no prever que los indicadores pueden ser afectados por externalidades, por lo que se recomienda elegir los menos sesgados. Los autores también hacen énfasis en la necesidad de seleccionar el nivel de medición, no exigir medidas que no se puedan obtener y garantizar la replicabilidad de las medidas ${ }^{19}$.

Por el lado de la agregación los retos son tres: seleccionar el nivel de agregación que se desea, con el objetivo de hacer los datos más manejables ${ }^{20}$. Sin embargo, la tendencia de generar datos reducidos olvida el hecho de que los indicadores utilizados

14 En él se analizan los siguientes 9 índices de democracia: ACLP, Arat, Bollen, Coppedge y Reinicke, Freedom House, Gasiorowski, Hadenius, Polity IV, Vanhanen.

15 Este problema dificulta la obtención de referentes empíricos.

16 Permite el estudio de numerosas cuestiones empíricas pero los análisis suelen ser de poca profundidad.

17 Es decir, que los componentes de los atributos manifiesten aspectos mutuamente excluyentes.

18 Por citar algunos ejemplos el de "derechos socioeconómicos" y "derechos de propiedad" del Freedom House, el de "Cargos" del ACLP, "Efectividad del legislativo" de Arat, "efectividad de las elecciones" de Hadenius. Estos reflejan atributos de eficacia, cultura política, procesos electorales.

19 Para que esto pueda ser posible los analistas deben registrar y divulgar sus reglas de medición, el proceso de medición y los datos desagregados.

20 Ante esto los autores advierten que un nivel superior de agregación puede llevar a la perdida de validez, ya que se disipa información acerca de la variación sistemática entre los casos. 
para medir los atributos desagregados pueden no necesariamente medir un fenómeno unidimensional y, por lo tanto, los resultados pueden ser multidimensionales. Los otros dos retos son la selección de la regla de agregación, lo que hace alusión a las técnicas de ponderación que deben estar sustentados en la teoría y, finalmente. la divulgación y el registro de las reglas de agregación y los datos agregados.

En el análisis que Munck y Verkuilen realizan sobre los índices de democracia que se han elaborado desde 1948, determinan que:

unos son más sofisticados que otros por la forma en que abordaron los retos de cada una de las dimensiones, éstos son el de ACLP, Coppedge y Reinicke, Hadenius y los que presentan menor rigor metodológico son los de Freedom House, Gasiorowski y Vanhanen. (Munck y Verkuilen, 2002, p. 433).

Sin embargo, y pese a los problemas que se han presentado en la elaboración de los datos sobre la democracia, es mejor que no tener ninguno y recomiendan a los estudiosos utilizar los que tienen a su disposición.

\subsection{Evolución de IDD-Lat por subregiones}

Para la selección de los casos para estudiar se utilizará la base de datos ofrecida por el Índice de desarrollo democrático de América Latina IDD-lat elaborada por La Fundación Konrad Adenauer Stiftung y Polilat.com. durante el período comprendido entre 2002 y 2007. A pesar de que en el estudio de Munk y Verkuilen no se analiza este índice, porque fue realizado con antelación, y se hace énfasis en la fortaleza de algunos específicos, se utilizará éste debido a que existe información desagregada y de fácil acceso. El índice de Freedom House, cuya información también es asequible, es preferible no utilizarlo dado las diversas críticas que se le han realizado ${ }^{21}$.

Además, se escogió este índice porque de acuerdo a lo expuesto en términos metodológicos, el IDD-lat cumple con algunos retos de conceptualización, mediante el establecimiento de los atributos del concepto representados en IV dimensiones claramente desagregadas en sus diversos componentes. En cuanto a la medición, se establecen los indicadores para cada componente y existe la divulgación y el registro de las reglas de medición, el proceso de medición así como de la agregación y los datos agregados. Sin embargo, no es posible encontrar el soporte teórico en ninguna de las tres etapas y tampoco se establece la selección del nivel de medición ni del nivel

21 Según Munk y Verkuilen: Inclusión de muchos componentes en cada uno de sus dos atributos, no proporcionan un conjunto claro de reglas de medición, problemas con respecto a la selección del nivel de medición, la no divulgación de datos desagregados, el proceso de medición a cambiado varias veces lo que impide hacer un análisis horizontal sin ajustar los datos, la consistencia interna de sus datos es cuestionable. 
de agregación ${ }^{22}$. Así mismo, son cuestionables algunos de los indicadores utilizados para medir los componentes del atributo, en algunos casos se presentan problemas de redundancia y la base de datos nueva limita considerablemente el análisis.

La región de América Latina conformada por 20 países, posee una subregionalización que por sus características históricas, cercanía geográfica e incluso por los procesos de integración comercial que se han desarrollado durante las últimas décadas permiten establecerlas. Las subregiones que utilizaremos para nuestro estudio son: Subregión Central ${ }^{23}$, Subregión Andina ${ }^{24}$ y Región del Cono Sur. ${ }^{25}$

Gráfica 1. Evolución promedio IDD-lat de la región y las subregiones 2002-2007

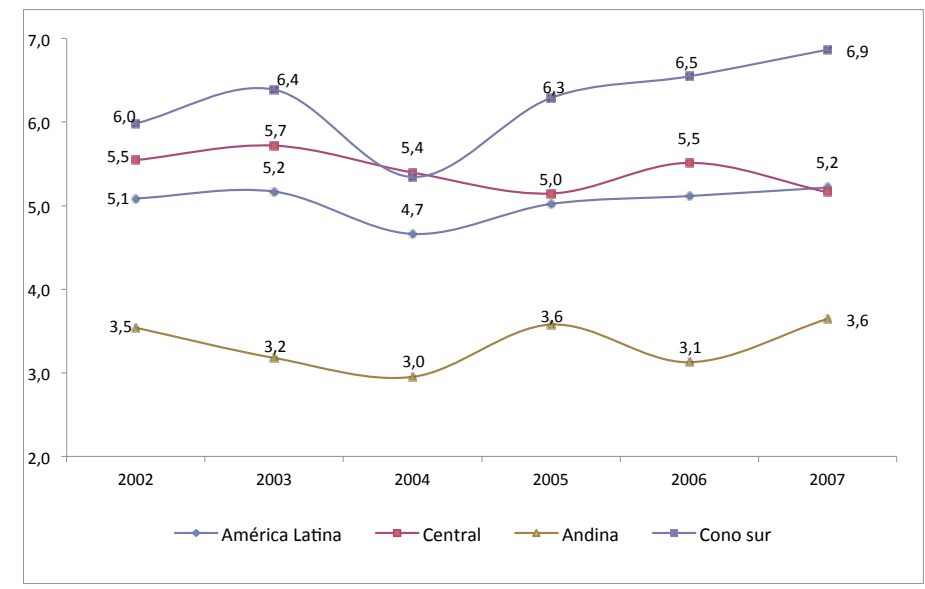

Gráfica elaborada por la autora con base en los datos del IDD-lat 2002-2007

Cuando se analiza la evolución del IDD-Lat promedio por subregiones se observa que la región del Cono Sur está por encima del promedio latinoamericano, desde el comienzo hasta el final del periodo de análisis. En 2007 la ventaja del índice de esta subregión frente al índice promedio de América Latina es de 1.7 puntos. Esto se explica por los buenos índices obtenidos por Chile y Uruguay que estuvieron en 3.5 y 2.5 puntos por encima del promedio de la subregión respectivamente. Sin embargo, se observa un alto contraste con el índice de Paraguay (el más bajo de la subregión) que alcanza una diferencia de 3.0 puntos en el 2007.

22 Consultar las cuestiones metodológicas del IDD-lat en www.idd-lat.org

23 México, Guatemala, Honduras, El Salvador, Nicaragua, Costa Rica y Panamá, se excluye a República Dominicana debido a que no existen datos para el periodo completo de análisis.

24 Colombia, Perú, Venezuela, Ecuador y Bolivia.

25 Argentina, Brasil, Uruguay, Paraguay y Chile. 
Gráfica 2. Evolución IDD-lat por países de la Subregión del Cono Sur 2002-2007

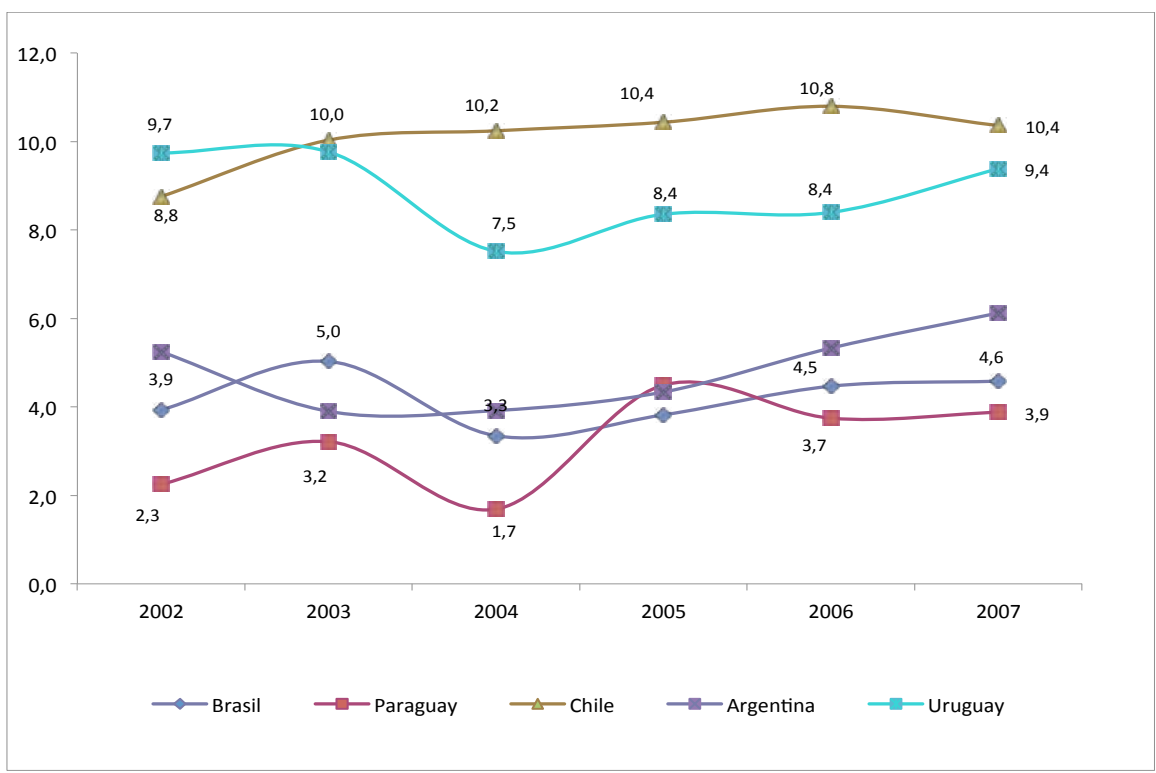

Gráfica elaborada por la autora con base en los datos del IDD-lat 2002-2007

En el caso de la Subregión Andina, la que ostenta los índices de democratización más bajos de toda la Región, el panorama no ha cambiado mucho durante los últimos 5 años. En el 2007 el promedio subregional es inferior al promedio de América Latina en 1.6 puntos. Colombia y Perú superan al promedio subregional en 1.2 y 0.5 puntos respectivamente, sin embargo, sus índices son aún más bajos que el promedio regional. La menor calificación es para Venezuela que estuvo por debajo del promedio regional en 0.7 puntos. 
Gráfica 3. Evolución IDD-lat por países la Subregión Andina 2002-2007

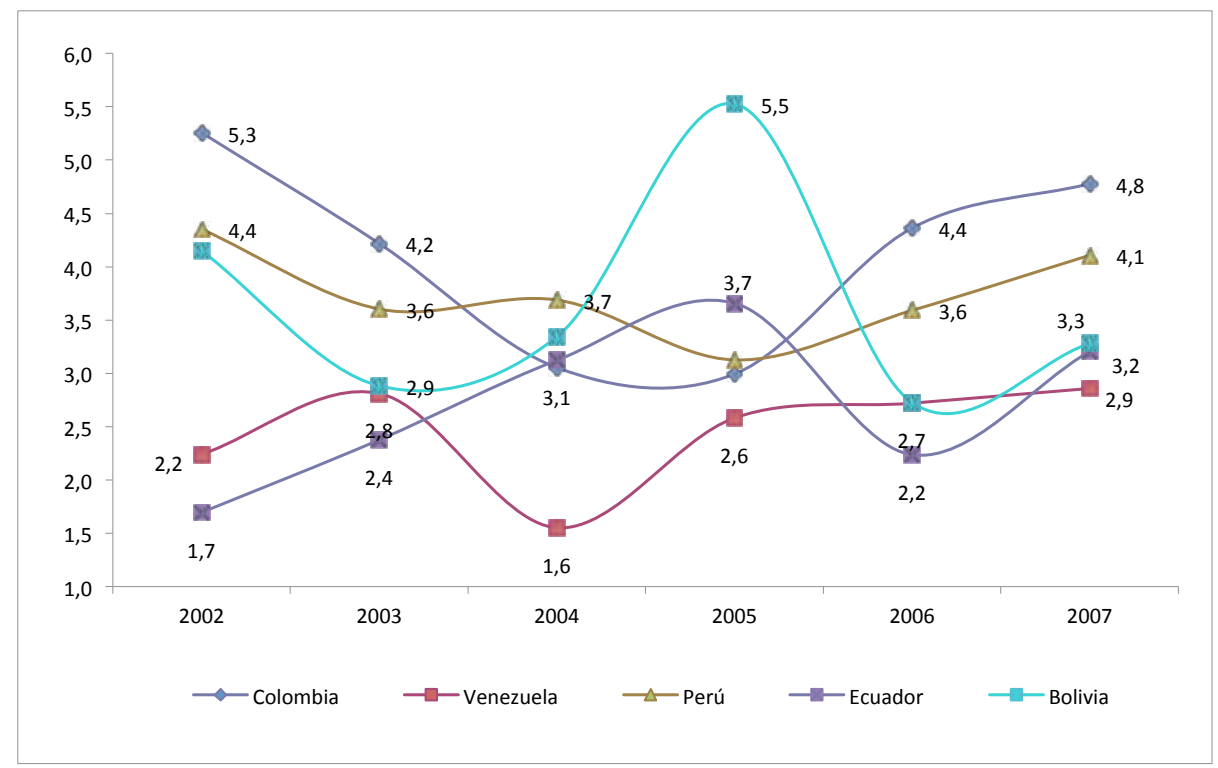

Gráfica elaborada por la autora con base en los datos del IDD-lat 2002-2007

La subregión central se encuentra con índices que lo sitúan dentro del promedio de América Latina, sin embargo, es la única subregión que disminuyó su calificación en 0.3 puntos durante 2002 y 2007. En ella también se evidencia la brecha existente entre Costa Rica, país con el mejor índice y Nicaragua con el peor, la diferencia es de 7 puntos. 
Gráfica 4. Evolución IDD-lat por países la subregión Central 2002-2007

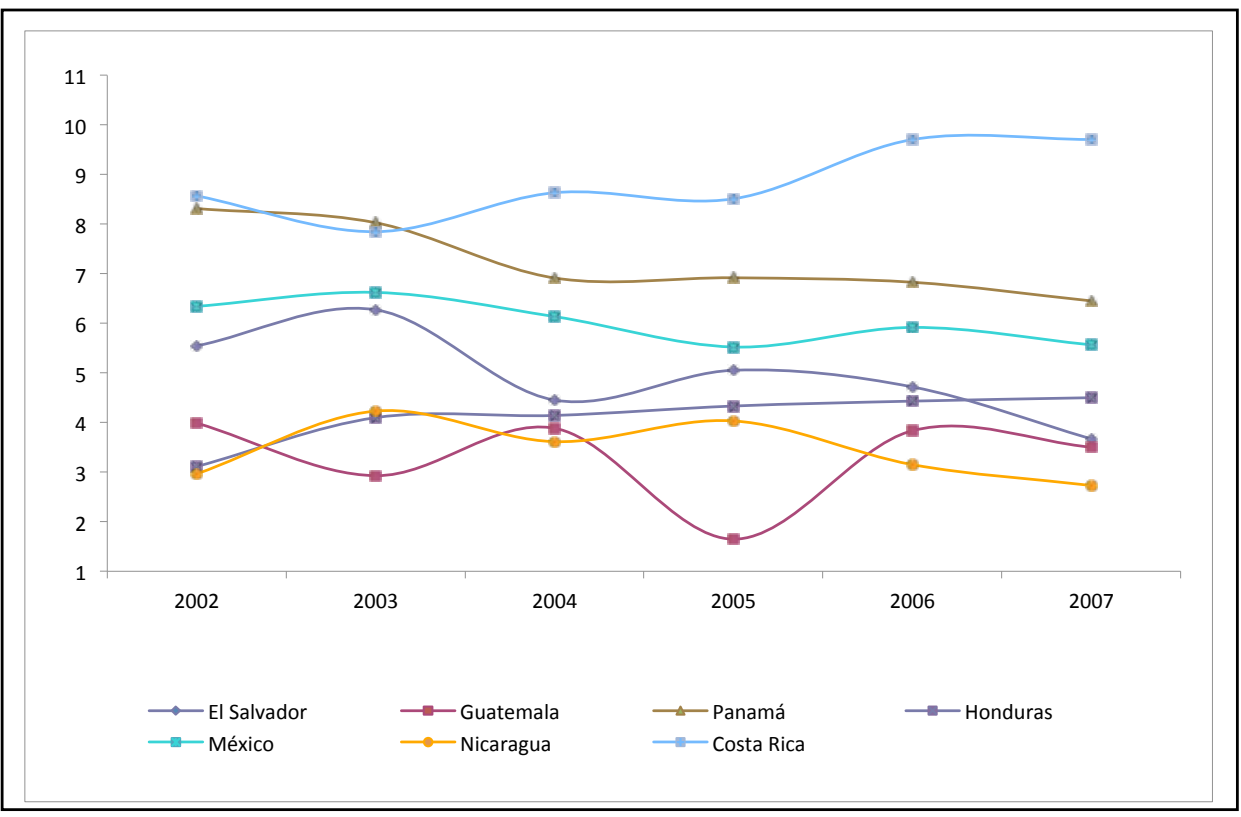

Gráfica elaborada por la autora con base en los datos del IDD-lat 2002-2007

Ahora bien, frente a esta panorámica regional es evidente que los países con índices democráticos más altos en el 2007 son Chile $(10,3)$ Costa Rica $(9,7)$ y Uruguay $(9,3)$, Colombia a pesar de poseer el mejor índice de la subregión andina ocupa el octavo puesto $(4,8)$ en el ranking e incluso está por debajo del promedio regional $(5,2)$. Y los que poseen los índices más bajos son Nicaragua $(2,7)$, Venezuela $(2,8)$ y Ecuador $(3,2)$. La concentración de los países mejor rankiados en la Subregión del Cono Sur y la de los peor rankiados en la Subregión Andina, no nos permite hacer un análisis comparativo de la relación causal, desde el punto de vista de las subregiones, porque obtendríamos tan sólo casos de dos subregiones.

\subsection{Selección de los casos}

Por lo tanto, la selección de los casos de nuestro análisis comparativo se hará mediante observación de las principales variaciones en el IDD-lat entre 2002 y 2007 , para contrastarlo con las variaciones en el PIB per cápita de esos países durante 
el mismo periodo. De esta manera podemos analizar índices de países que no son necesariamente los mejores, ni tampoco los peores, si no que comparamos los países que hayan presentado la mayor variabilidad en cada una de las subregiones.

Gráfica 5. Evolución dentro del ranking del IDD-lat de los países de América Latina 2002-2007

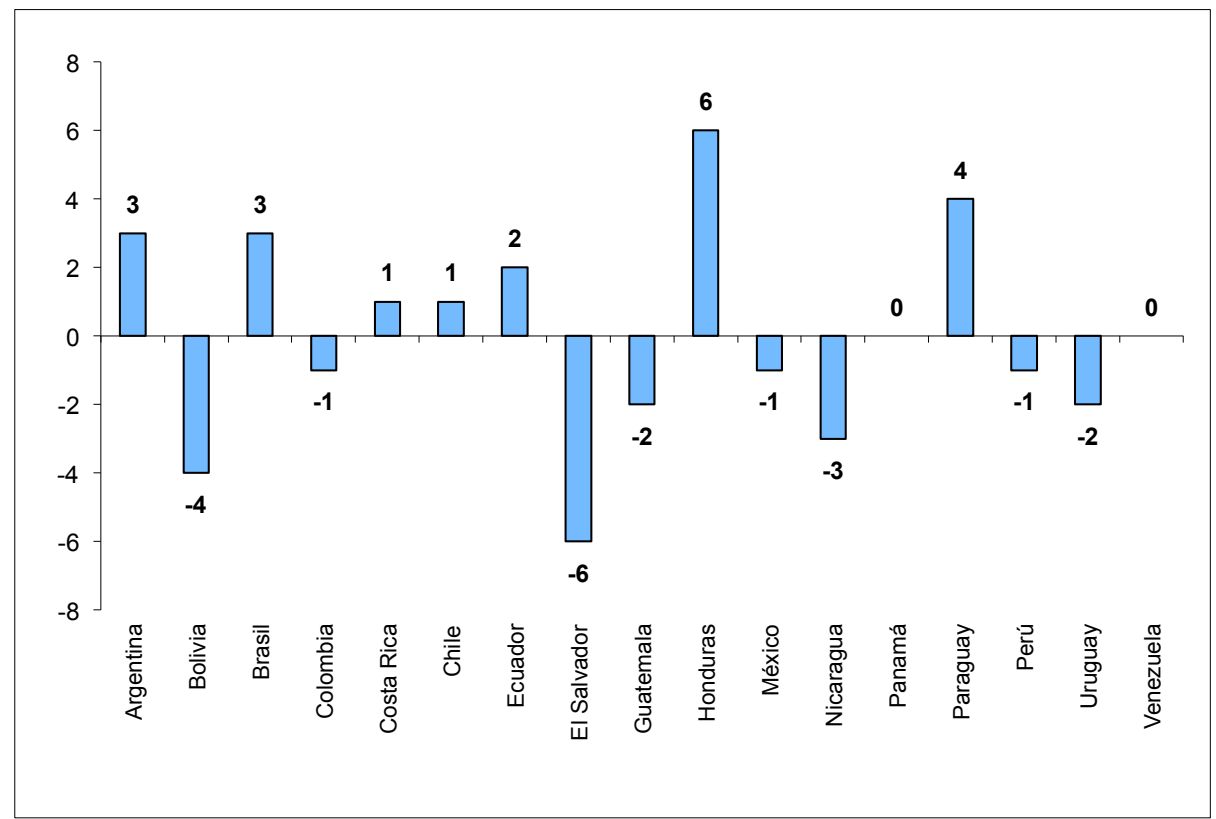

Cálculos de la autora con base en los datos del IDD-lat 2002-2007

De acuerdo con lo anterior el país que mostró el mayor progreso en su índice fue Honduras cuya calificación aumentó en 1,6 puntos, mejorado su ranking en 6 posiciones (del puesto 13 en el 2002 pasó a ocupar el puesto 7 en el 2007). El segundo país que presentó el mayor progreso dentro del ranking latinoamericano fue Paraguay, que ganó 4 posiciones (del puesto 15 en el 2002 al puesto 11 en el 2007). En el caso contrario, el país que perdió más posiciones fue El salvador (del puesto 6 en el 2002 al puesto 12 en el 2007), De igual forma se observa que Bolivia desmejoró en su indicador y perdió 4 posiciones (del puesto 10 en el 2002 al puesto 14 en el 2007). De manera que estos países que han experimentado las mayores variaciones y que se caracterizan por tener un índice de democracia no muy favorable, (se encuentran por debajo del promedio regional) serán nuestros casos de comparación. 
Tabla 1. Posición ranking IDD-lat 2002-2007

\begin{tabular}{|l|c|c|c|c|c|c|}
\hline \multicolumn{1}{|c|}{ PAÍS } & 2003 & RANKING & 2007 & RANKING & DIFERENCIA & POSICIONES \\
\hline Argentina & 5,2 & 8 & 6,1 & 5 & 0,9 & 3 \\
\hline Bolivia & 4,2 & 10 & 3,3 & 14 & $-0,9$ & -4 \\
\hline Brasil & 3,9 & 12 & 4,6 & 9 & 0,7 & 3 \\
\hline Colombia & 5,3 & 7 & 4,8 & 8 & $-0,5$ & -1 \\
\hline Costa Rica & 8,6 & 3 & 9,7 & 2 & 1,1 & 1 \\
\hline Chile & 8,8 & 2 & 10,4 & 1 & 1,6 & 1 \\
\hline Ecuador & 1,7 & 17 & 3,2 & 15 & 1,5 & 2 \\
\hline El Salvador & 5,5 & 6 & 3,7 & 12 & $-1,9$ & -6 \\
\hline Guatemala & 4,0 & 11 & 3,5 & 13 & $-0,5$ & -2 \\
\hline Honduras & 3,1 & 13 & 4,5 & 7 & 1,4 & 6 \\
\hline México & 6,3 & 5 & 5,6 & 6 & $-0,8$ & -1 \\
\hline Nicaragua & 3,0 & 14 & 2,7 & 17 & $-0,2$ & -3 \\
\hline Panamá & 8,3 & 4 & 6,5 & 4 & $-1,9$ & 0 \\
\hline Paraguay & 2,3 & 15 & 3,9 & 11 & 1,6 & 4 \\
\hline Perú & 4,4 & 9 & 4,1 & 10 & $-0,2$ & -1 \\
\hline Uruguay & 9,7 & 1 & 9,4 & 3 & $-0,4$ & -2 \\
\hline Venezuela & 2,2 & 16 & 2,9 & 16 & 0,6 & 0 \\
\hline
\end{tabular}

Elaborado por la autora con base en datos IDD 2002-2007.

\section{La democracia y el desarrollo en América Latina}

Es necesario aclarar que este trabajo realiza observaciones limitadas, conclusiones netamente descriptivas y no análisis sofisticados basados en regresiones, por lo que no afirma la existencia de relaciones causales y sólo busca observar si la teoría desarrollada es aplicable a estos casos.

Es observable la existencia de una relación causal entre democracia y desarrollo económico en Paraguay y Honduras, países que mejoraron en su IDD-lat y que al mismo tiempo presentaron avances en su nivel de desarrollo en 3,3 y 0,8 puntos respectivamente. Era de esperarse que el progreso de Honduras en términos de desarrollo fuera mucho mayor, debido a su variación dentro del ranking de la Región (1,7 puntos), pero no lo fue, ya que Paraguay lo superó en 2,5 puntos. Ello permite establecer la existencia de variables intervinientes de orden institucional, distintas a las mencionadas en este trabajo, que influyen en la percepción que se tiene del régimen. 
Tabla 2. Evolución IDD-lat y PIB per cápita países de estudio comparado (2002-2007)

\begin{tabular}{|c|c|c|c|c|c|c|c|c|}
\hline PAÍS & INDICADOR & 2002 & 2003 & 2004 & 2005 & 2006 & 2007 & $\begin{array}{c}\text { VARIACIÓN } \\
2002 / 2007\end{array}$ \\
\hline \multirow{3}{*}{ Paraguay } & Índice & 2,3 & 3,2 & 1,7 & 4,5 & 3,7 & 3,9 & 1,6 \\
\hline & Ranking & 15 & 13 & 16 & 8 & 12 & 11 & 4,0 \\
\hline & PIB per cápita* & $-2,0$ & $-4,0$ & $-5,8$ & $-0,5$ & $-2,5$ & 1,3 & 3,3 \\
\hline \multirow{3}{*}{ Bolivia } & Índice & 4,2 & 2,9 & 3,3 & 5,5 & 2,7 & 3,3 & $-0,9$ \\
\hline & Ranking & 10 & 15 & 13 & 5 & 15 & 14 & $-4,0$ \\
\hline & PIB per cápita* & 2,5 & $-1,9$ & 0,1 & $-0,6$ & 0,2 & 0,6 & $-1,9$ \\
\hline \multirow{3}{*}{ El Salvador } & Índice & 5,5 & 6,3 & 4,5 & 5,1 & 4,7 & 3,7 & $-1,9$ \\
\hline & Ranking & 6 & 6 & 6 & 7 & 7 & 12 & $-6,0$ \\
\hline & PIB per cápita* & 1,6 & 1,4 & 0,2 & $-0,2$ & 0,4 & 0,4 & $-1,2$ \\
\hline \multirow{3}{*}{ Honduras } & Índice & 3,1 & 4,1 & 4,1 & 4,3 & 4,4 & 4,5 & 1,4 \\
\hline & Ranking & 13 & 10 & 7 & 10 & 9 & 7 & 6,0 \\
\hline & PIB per cápita* & 0,1 & $-4,5$ & 3,0 & 0,0 & 0,1 & 0,9 & 0,8 \\
\hline
\end{tabular}

Elaborado por la autora con base en datos de la CEPAL y el IDD-lat 2002-2007

*Expresado en tasas anuales de variación

Por su parte en El Salvador y Bolivia se presenta también evidencia de esta relación causal. La variación negativa dentro del ranking del IDD-lat concuerda con una disminución en el nivel de desarrollo de -1,2 y -1,9 puntos respectivamente. Sin embargo, también se evidencia la existencia de otras variables intervinientes que influyen en el IDD-lat, debido a que la variación negativa más significativa en éste que se presentó en El Salvador $(-1,9)$, no concuerda con la más significativa del desarrollo que fue en Bolivia (-1,9).

Por lo tanto, puede concluirse que los signos de variación en el IDD-lat, coinciden con los que se presentaron en el indicador de desarrollo, pero que las magnitudes de progreso que esperaba encontrarse no fueron concordantes con la teoría. El país que más progresó en el IDD-lat (Honduras) aunque mejoró un su nivel de desarrollo, no presentó la mayor variación y estuvo 2,5 puntos por debajo de Paraguay, país que experimentó el mayor avance en términos de desarrollo. La situación es igual en el caso de los países con variación negativa en el índice de democracia. 
Gráfica 6. VARIACIÓN IDD-Lat y PIB PER CÁPITA POR PAÍSES 2002-2007

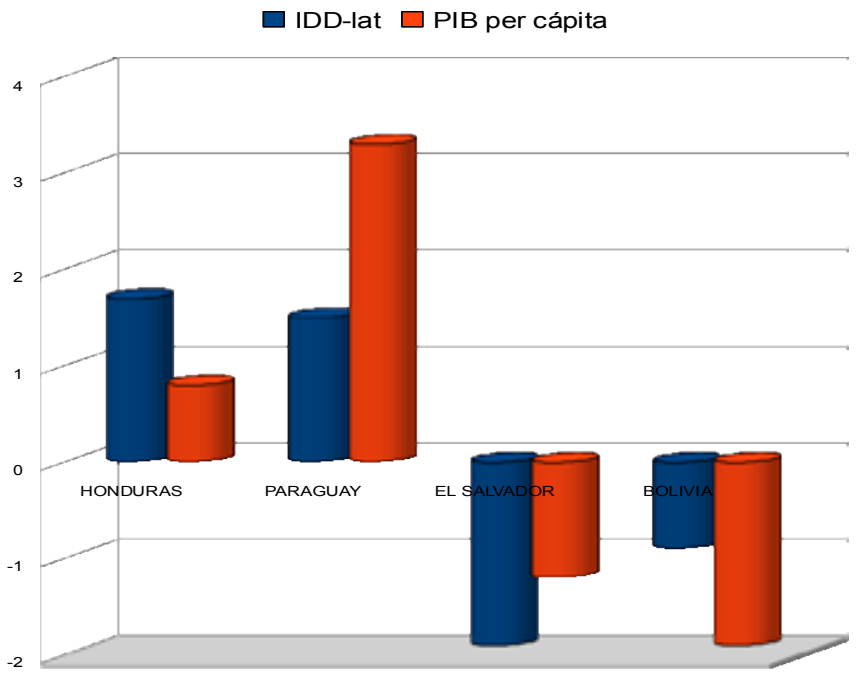

Cálculos de la autora con base en los datos del IDD-lat 2002-2007

Gráfica 7. Evolución PIB per cápita e IDD-lat Paraguay 2002-2007

Paraguay

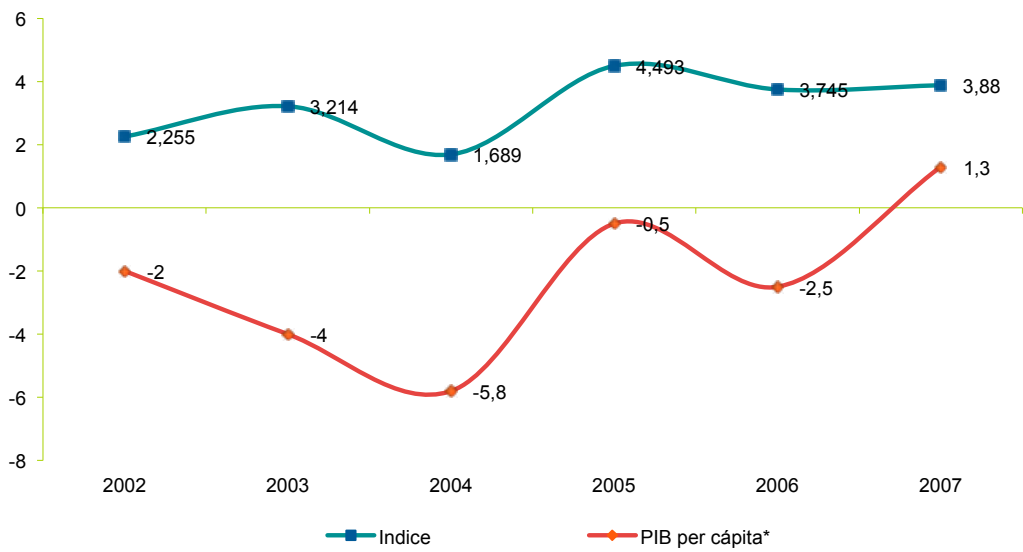

Elaborado por la autora con base en datos de la CEPAL y el IDD-lat 2002-2007

*Expresado en tasas anuales de variación 
Gráfica 8. Evolución PIB per cápita e IDD-lat El Salvador 2002-2007

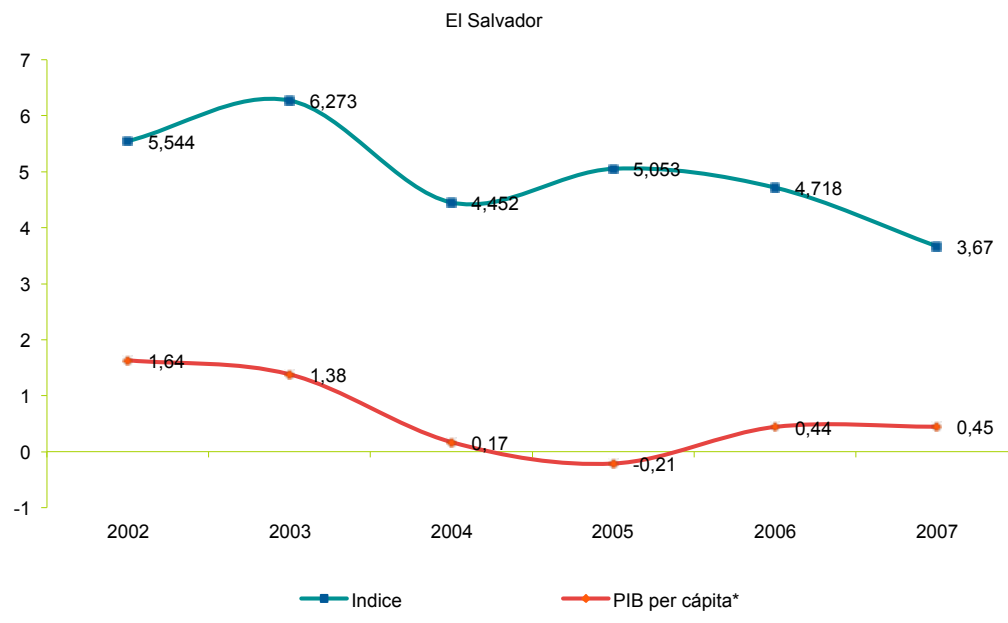

Elaborado por la autora con base en datos de la CEPAL y el IDD-lat 2002-2007

*Expresado en tasas anuales de variación

Gráfica 9. Evolución PIB per cápita e IDD-lat Honduras 2002-2007

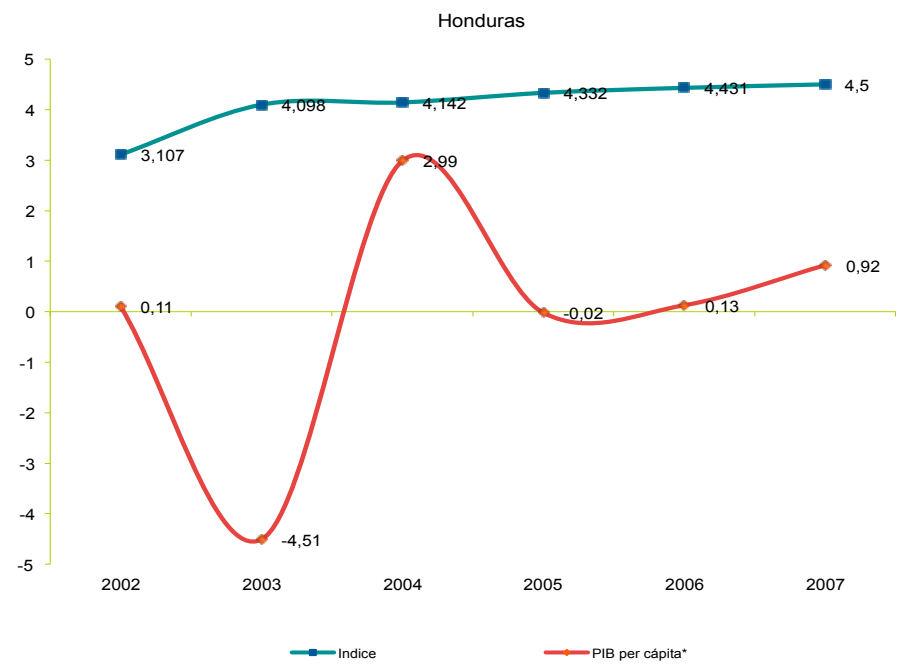

Elaborado por la autora con base en datos de la CEPAL y el IDD-lat 2002-2007.

*Expresado en tasas anuales de variación. 
Gráfica 10. Evolución PIB per cápita e IDD-lat Bolivia 2002-2007

Bolivia

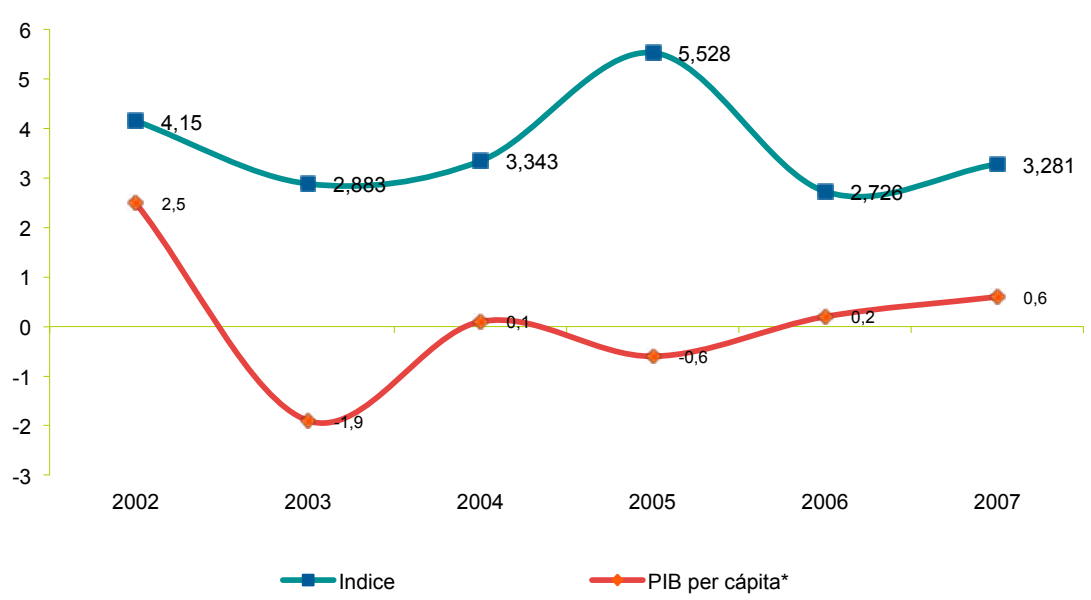

Elaborado por la autora con base en datos de la CEPAL y el IDD-lat 2002-2007

*Expresado en tasas anuales de variación

En los resultados obtenidos se aplica parcialmente la relación causal planteada en la teoría. Sin embargo, dadas las explicaciones que se presentaron con antelación sobre el riesgo de utilizar el PIB per cápita como indicador de desarrollo, observaremos la evolución del nivel de pobreza y de desigualdad en estos países, variables directamente relacionadas con los resultados obtenidos de las decisiones políticas tomadas en el parlamento.

Tabla 3. EVOLUCIÓN IDH E IPH 2000- 2006

\begin{tabular}{|l|c|c|c|c|c|c|}
\hline & \multicolumn{3}{|c|}{ IDH } & \multicolumn{3}{c|}{ IPH } \\
\hline PAÍS & 2000 & 2006 & VARIACIÓN & 2000 & 2006 & VARIACIÓN \\
\hline Paraguay & 0,74 & 0,75 & 0,01 & 20,2 & 21,8 & 1,6 \\
\hline Honduras & 0,66 & 0,7 & 0,04 & 59,4 & 50,7 & $-8,7$ \\
\hline El Salvador & 0,71 & 0,73 & 0,02 & 48,3 & 37,2 & $-11,1$ \\
\hline Bolivia & 0,67 & 0,69 & 0,02 & 67,2 & 62,7 & $-4,5$ \\
\hline
\end{tabular}

Elaborado por la autora con base en datos informe de desarrollo humano 2000-2006 PNUD 
Se observa que aunque ha existido progreso en el Índice de Desarrollo Humano entre el 2000 y el 2006 este avance es irrisorio para los cuatro casos. Bolivia el país que cuenta con el índice más desfavorable en términos tanto de desarrollo humano como de pobreza humana presenta un comportamiento consecuente con poseer el índice de democracia más bajo $(3,3)$.

Sin embargo, este no puede ser el único argumento de explicación ya que si fuera cierto, El Salvador que presentó la mayor reducción de la pobreza (-11\%) hubiera mejorado su índice de democracia y por el contrario fue el que presentó el mayor retroceso $(-1,9)$.

En Honduras se evidencia el mayor avance en términos de desarrollo humano pero no goza del mejor índice de democracia. No obstante, alcanzó resultados significativos en términos de reducción de pobreza, que pueden explicar la mayor variación positiva en su índice. Sin embargo, nuevamente esta relación se ve cuestionada por Paraguay, que ostenta los mejores niveles de desarrollo y pobreza humana, pero que incluso aumentó su porcentaje de población por debajo de la línea de pobreza sin afectar su índice de democracia.

\section{Conclusiones}

Como se dijo anteriormente, existe abundante literatura en torno al establecimiento de relaciones causales entre democracia y desarrollo económico. En algunos casos se señala que las buenas condiciones socioeconómicas favorecen el establecimiento de la democracia y el mantenimiento del régimen; en otros, por el contrario, se sostiene que la democracia como régimen basado en los principios de igualdad, libertad y representatividad, estimula la mejora continua de las condiciones de vida de la población, en la medida en que las decisiones políticas están sometidas al control ciudadano en la contienda electoral.

Pese a la dificultad de medir tanto la democracia como el desarrollo económico, debido al riesgo que se corre cuando se busca reflejar una realidad social que tiene mucho de subjetiva, mediante estudios cuantitativos que al sintetizar diversos atributos del concepto excluyen información relevante, reduciendo una realidad compleja a un dato, que en muchos casos expresa una realidad multidimensional, y pese a las diversas críticas que actualmente existen con respecto a los indicadores que se han construido y que se utilizan para estudiar estos dos conceptos, la observación realizada en este trabajo permite concluir que, independientemente de la dirección de la relación causal que señale la teoría, bien sea de la democracia hacía el desarrollo, del desarrollo hacía la democracia o en algunos casos en ambas direcciones, ninguno de estos conceptos es garantía única de la existencia del otro.

Cuestionar la democracia implica establecer la influencia que ejercen las reglas del juego que determina su desarrollo. Por tanto, es evidente que en América Latina 
aspectos como la debilidad institucional, el carácter disfuncional de su sistema judicial y la violación de los derechos humanos, entre otros, han obstaculizado la consolidación de la democracia, concepto que ya de por sí tiene un alto contenido utópico en su definición. Si el componente de representatividad, fuese reforzado con una adecuada rendición de cuentas y si el ejercicio democrático electoral se convirtiera en un mecanismo efectivo de premios y castigos al desempeño político de quien ejerce el poder, sería mucho más fácil afirmar que la democracia incentiva el desarrollo económico de los pueblos y que los pueblos que están satisfechos con su evolución económica, política y social es donde más legitimado, respaldado y apoyado está el régimen.

De la observación realizada en Bolivia, El Salvador, Honduras y Paraguay se concluye que en los cuatro casos la relación causal entre democracia y desarrollo económico es refutable, dado que si bien los mejores índices de desarrollo democrático son consecuentes con progresos en materia de desarrollo económico experimentados por los países, las variaciones en los indicadores no son consecuentes en cuanto a magnitudes, por lo que se evidencia la existencia de variables intervinientes posiblemente de orden institucional que pueden estar perturbando esta relación. Así pues, el país que más progresó en el IDD-lat (Honduras) aunque mejoró un su nivel de desarrollo económico, no presentó la mayor variación en este indicador, incluso estuvo 2,5 puntos por debajo de Paraguay, país que experimentó el mayor avance en términos de desarrollo económico durante el período de análisis. La situación es igual en el caso de los países con variación negativa en el IDD-lat, dado que El Salvador país que más desmejoró en el indicador, no fue necesariamente el que más empeoró en términos de desarrollo económico.

La democracia como régimen político basado en igualdad, libertad y justicia contempla intrínsecamente el bienestar social, es una ideología cuyos principios son posibles bajo esquemas de desarrollo económico. Sin embargo, este instrumento responde a consecuencias sistémicas, en donde la calidad de las instituciones determinan el grado de utopía del régimen. No es la democracia la que no opera en pro del desarrollo son las decisiones políticas las que influye directamente en los resultados obtenidos. Por ello, es un error decir que la democracia no funciona, es la política la que no funciona.

\section{REFERENCIAS}

Dahl, Robert, (1989). La Poliarquía. Tecnos. Madrid. Capítulos 1, 5, 6 y 10.

Dahl, Robert, (2002). La democracia y sus críticos, Paidós, Estado y Socidad, España.

Diamond, Larry, (1999) Hartlyn Jonathan, Linz Juan, Lipset, Seymour Martin editores. Democracy in Developing Countries - Latin America. Lynne Rienner Publishers. Pp. 1-608. 
IDD-lat (2002), Cuestiones metodológicas en: http://www.idd-lat.org/, consulado el 2 de enero del 2002.

IDD-lat 2002, 2003, 2004, 2005, 2006, 2007, análisis por países en: http://www.iddlat.org/, consulado el 2 de enero del 2002.

Lipset, Seymour Martin, (1959). Some Social Requisites of Democracy: Economic Development and Political Legitimacy. Americam Political Science Review. Pp. 69-105

Mainwaring Scott y Pérez Aníbal, (2004). Nivel de desarrollo y democracia: el excepcionalísimo latinoamericano, 1945-1996. Revista América Latina Hoy. Pp. 189-248.

Munck, Gerardo y Verkuilen Jay, (2012). Conceptualizando y midiendo la democracia: Una evaluación de índices alternativos. Política y gobierno, Vol. IX, No. 2. Pp. 403-441.

Programa de Naciones Unidas para el Desarrollo PNUD, (2004). El desarrollo de la democracia en América Latina, en La democracia en América Latina. Hacia una democracia de ciudadanos y ciudadanas. Pp. 31-71

Porzecanski, Rafael, (2000). Tipos de democracia, políticas económicas y equidad social en América Latina. En biblioteca virtual de Ciencias Sociales en América Latina y el Caribe, de la red de centros miembros de CLACSO. Pp. 1-39.

Russett, Bruce, (1993). Peace among Democracies. Scientific American. Pp. 31-63.

Sartori, Giovanni, (1992). Democracia, en Elementos de teoría política. Alianza Universidad de Madrid. Pp. 27-62.

Sen, Amartya, (2000). Desarrollo y libertad. Editorial Planeta. Madrid-España. 


\section{ANEXO A}

\section{EVOLUCIÓN IDD-lat Y ALGUNAS VARIABLES DEL DESARROLLO 2002-2007}

\begin{tabular}{|c|c|c|l|l|l|}
\hline PAÍS & IDD-lat & PIB per cápita & G. Salud & G E ducación & Pobreza \\
\hline PARAGUAY & $\uparrow$ & $\downarrow$ & $\downarrow$ & $\uparrow$ & $\downarrow$ \\
\hline BOLIVIA & $\downarrow$ & $\longrightarrow$ & $\downarrow$ & $\uparrow$ & $\downarrow$ \\
\hline HONDURAS & $\uparrow$ & $\longrightarrow$ & $\longrightarrow$ & $\uparrow$ & $\downarrow$ \\
\hline EL SALVADOR & $\downarrow$ & $\uparrow$ & $\downarrow$ & $\uparrow$ & $\downarrow$ \\
\hline
\end{tabular}

Elaborado por la autora con base en datos IDD-lat 2002-2007 y CEPAL 2002-2007 


\section{ANEXO B}

\section{IID-lat anual por países y promedio regional y subregional 2002-2007}

\begin{tabular}{|l|c|c|c|c|c|c|}
\hline \multicolumn{7}{|}{ IDD-lat 2002- 2007 } \\
\hline \multicolumn{1}{|c|}{ PAÍS } & $\mathbf{2 0 0 2}$ & $\mathbf{2 0 0 3}$ & $\mathbf{2 0 0 4}$ & $\mathbf{2 0 0 5}$ & $\mathbf{2 0 0 6}$ & $\mathbf{2 0 0 7}$ \\
\hline Argentina & 5,2 & 3,9 & 3,9 & 4,3 & 5,3 & 6,1 \\
\hline Bolivia & 4,2 & 2,9 & 3,3 & 5,5 & 2,7 & 3,3 \\
\hline Brasil & 3,9 & 5,0 & 3,3 & 3,8 & 4,5 & 4,6 \\
\hline Colombia & 5,3 & 4,2 & 3,1 & 3,0 & 4,4 & 4,8 \\
\hline Costa Rica & 8,6 & 7,8 & 8,6 & 8,5 & 9,7 & 9,7 \\
\hline Chile & 8,8 & 10,0 & 10,2 & 10,4 & 10,8 & 10,4 \\
\hline Ecuador & 1,7 & 2,4 & 3,1 & 3,7 & 2,2 & 3,2 \\
\hline El Salvador & 5,5 & 6,3 & 4,5 & 5,1 & 4,7 & 3,7 \\
\hline Guatemala & 4,0 & 2,9 & 3,9 & 1,6 & 3,8 & 3,5 \\
\hline Honduras & 3,1 & 4,1 & 4,1 & 4,3 & 4,4 & 4,5 \\
\hline México & 6,3 & 6,6 & 6,1 & 5,5 & 5,9 & 5,6 \\
\hline Nicaragua & 3,0 & 4,2 & 3,6 & 4,0 & 3,2 & 2,7 \\
\hline Panamá & 8,3 & 8,0 & 6,9 & 6,9 & 6,8 & 6,5 \\
\hline Paraguay & 2,3 & 3,2 & 1,7 & 4,5 & 3,7 & 3,9 \\
\hline Perú & 4,4 & 3,6 & 3,7 & 3,1 & 3,6 & 4,1 \\
\hline Uruguay & 9,7 & 9,8 & 7,5 & 8,4 & 8,4 & 9,4 \\
\hline Venenzuela & 2,2 & 2,8 & 1,6 & 2,6 & 2,7 & 2,9 \\
\hline Promedio América Latina & $\mathbf{5 , 1}$ & $\mathbf{5 , 2}$ & $\mathbf{4 , 7}$ & $\mathbf{5 , 0}$ & $\mathbf{5 , 1}$ & $\mathbf{5 , 2}$ \\
\hline Promedio Subregión Central & $\mathbf{5 , 5}$ & $\mathbf{5 , 7}$ & $\mathbf{5 , 4}$ & $\mathbf{5 , 1}$ & $\mathbf{5 , 5}$ & $\mathbf{5 , 2}$ \\
\hline Promedio Subregión Cono Sur & $\mathbf{6 , 0}$ & $\mathbf{6 , 4}$ & $\mathbf{5 , 3}$ & $\mathbf{6 , 3}$ & $\mathbf{6 , 5}$ & $\mathbf{6 , 9}$ \\
\hline Promedio Subregión Andina & $\mathbf{3 , 5}$ & $\mathbf{3 , 2}$ & $\mathbf{3 , 0}$ & $\mathbf{3 , 6}$ & $\mathbf{3 , 1}$ & $\mathbf{3 , 6}$ \\
\hline
\end{tabular}

Cálculos de la autora con base en datos IDD 2002-2007. SHAPE 